\title{
Isotopic Imprints of Mountaintop Mining Contaminants
}

\author{
Avner Vengosh, ${ }^{\dagger} *$ T. Ty Lindberg, ${ }^{\ddagger}$ Brittany R. Merola, ${ }^{\dagger}$ Laura Ruhl, ${ }^{\S}$ Nathaniel R. Warner, ${ }^{\dagger}$ \\ Alissa White, ${ }^{\dagger}$ Gary S. Dwyer, ${ }^{\dagger}$ and Richard T. Di Giulio ${ }^{\ddagger}$ \\ ${ }^{\dagger}$ Division of Earth and Ocean Sciences, Nicholas School of the Environment, Duke University, Durham, North Carolina 27708, \\ United States \\ ${ }^{\ddagger}$ Division of Environmental Sciences and Policy, Nicholas School of the Environment, Duke University, Durham, North Carolina \\ 27708, United States \\ ${ }^{\S}$ Department of Earth Sciences, University of Arkansas at Little Rock, Little Rock, Arkansas 72204, United States
}

\section{Supporting Information}

ABSTRACT: Mountaintop mining (MTM) is the primary procedure for surface coal exploration within the central Appalachian region of the eastern United States, and it is known to contaminate streams in local watersheds. In this study, we measured the chemical and isotopic compositions of water samples from MTM-impacted tributaries and streams in the Mud River watershed in West Virginia. We systematically document the isotopic compositions of three major constituents: sulfur isotopes in sulfate $\left(\delta^{34} \mathrm{~S}_{\mathrm{SO} 4}\right)$, carbon isotopes in dissolved inorganic carbon $\left(\delta^{13} \mathrm{C}_{\mathrm{DIC}}\right)$, and strontium isotopes $\left({ }^{87} \mathrm{Sr} /{ }^{86} \mathrm{Sr}\right)$. The data show that $\delta^{34} \mathrm{~S}_{\mathrm{SO} 4}$, $\delta^{13} \mathrm{C}_{\mathrm{DIC}}, \mathrm{Sr} / \mathrm{Ca}$, and ${ }^{87} \mathrm{Sr} /{ }^{86} \mathrm{Sr}$ measured in saline- and selenium-rich MTM impacted tributaries are distinguishable from those of the surface water upstream of mining impacts. These tracers can therefore be used to delineate and quantify the impact of MTM in watersheds. High $\mathrm{Sr} / \mathrm{Ca}$ and

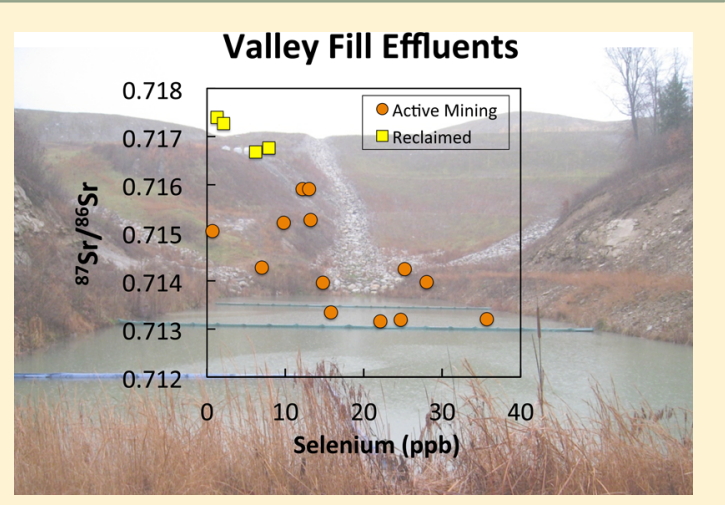
low ${ }^{87} \mathrm{Sr} /{ }^{86} \mathrm{Sr}$ characterize tributaries that originated from active MTM areas, while tributaries from reclaimed MTM areas had low $\mathrm{Sr} / \mathrm{Ca}$ and high ${ }^{87} \mathrm{Sr} /{ }^{86} \mathrm{Sr}$. Leaching experiments of rocks from the watershed show that pyrite oxidation and carbonate dissolution control the solute chemistry with distinct ${ }^{87} \mathrm{Sr} /{ }^{86} \mathrm{Sr}$ ratios characterizing different rock sources. We propose that MTM operations that access the deeper Kanawha Formation generate residual mined rocks in valley fills from which effluents with distinctive ${ }^{87} \mathrm{Sr} /{ }^{86} \mathrm{Sr}$ and $\mathrm{Sr} / \mathrm{Ca}$ imprints affect the quality of the Appalachian watersheds.

\section{INTRODUCTION}

In the eastern United States, surface mountaintop mining (MTM) has become the dominant technique for coal exploration, particularly in the central Appalachian coalfields of Kentucky, Virginia, West Virginia, and Tennessee, which cover about $48,000 \mathrm{~km}^{2}{ }^{1}$ As part of the MTM operations, several layers of sedimentary rocks are removed to access the underlying coal seams. The residual mined rocks, or overburden, are then typically placed in stream channels adjacent to the surface mines, creating valley fills (VF). These fills permanently bury headwater streams and alter the hydrology, chemistry, and biotic composition of source waters that feed the local streams and river systems. ${ }^{2-18}$

Carbonate mineral dissolution within the VF buffers the acidity that is generated from the oxidation of pyrite, and consequently, alkaline ( $\mathrm{pH}$ typically $>7$ ) and saline (TDS > $1500 \mathrm{mg} / \mathrm{L}$ ) effluents are generated in VF outflows. The VF effluents are characterized by high concentrations of $\mathrm{Ca}, \mathrm{Mg}, \mathrm{Sr}$, $\mathrm{SO}_{4}$, and $\mathrm{HCO}_{3}{ }^{15-17}$ The VF effluents also contain elevated concentrations of trace elements such as $\mathrm{Se}, \mathrm{As}$, and $\mathrm{Mn}$ that pose serious ecological risks to receiving streams, including toxic effects observed in fish in local watersheds. ${ }^{1,11,12,15,18}$ Recent findings show a cumulative aspect to discharge effluents from both active and reclaimed surface coal mines in West Virginia, where the increases in salinity, sulfate, and selenium are proportional to the upstream aerial extent of mining. ${ }^{15} \mathrm{~A}$ survey quantifying the extent of surface mining in southern West Virginia revealed that the extent of surface mining disturbance within a catchment is highly correlated with the ionic strength and sulfate concentrations of the receiving streams. $^{14}$

The majority of coal production from surface mines in the southern Appalachian of West Virginia is derived from the Middle Pennsylvanian Kanawha and Allegheny formations (Figures S1, S2, Supporting Information). The Kanawha Formation is composed mostly of sandstone, gray and black shale (Carbolith), siltstone, and hosts several coal seams, including the high quality Coalburg and Stockton coals. These coal seams represent $42 \%$ of West Virginia's original coal resources. The overlying Allegheny Formation is composed of cyclic sequences of sandstone, siltstone, shale, limestone, and

Received: March 25, 2013

Revised: August 2, 2013

Accepted: August 2, 2013 


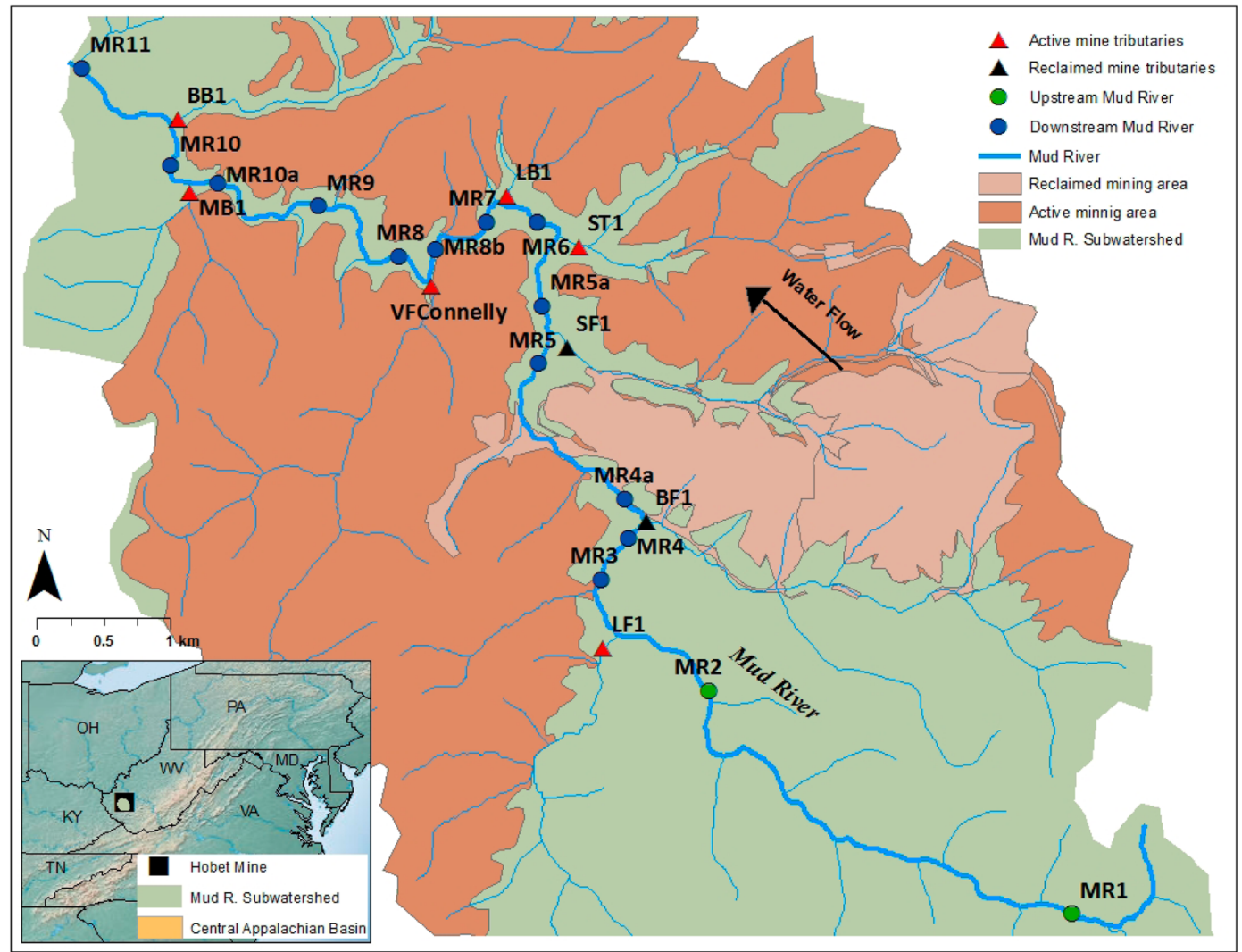

Figure 1. Sampling location map along the Mud River watershed in West Virginia. Note the distinction between the sampling sites of the upper (unaffected) Mud River (green circles), downstream Mud River (blue circles), tributaries from reclaimed mines (black triangles), and active mines (red triangles).

coal, including the No. 5 and No. 6 coal seams. Both formations contain a wide range of sulfur content $(0.01-10 \%)$ in the forms of organic sulfur and pyrite mineral ${ }^{19-21}$ (Figure S1, Table S1, Supporting Information).

Previous studies have evaluated the chemical and isotopic compositions of acid mine drainage that originated from subsurface coal mining. ${ }^{22-31}$ This study explores, for the first time, the stable isotope ratios of the major constituents in VF effluents and their impact on the isotopic variations in the receiving stream waters. We used stable carbon isotopes to delineate the sources of dissolved inorganic carbon $\left(\delta^{13} \mathrm{C}_{\mathrm{DIC}}\right)$ and sulfur isotopes for dissolved sulfate $\left(\delta^{34} \mathrm{~S}_{\mathrm{SO} 4}\right)$. We also used dissolved strontium isotopes $\left({ }^{87} \mathrm{Sr} /{ }^{86} \mathrm{Sr}\right)$ as a proxy for selenium contamination, given the high correlation between $\mathrm{Sr}$ and $\mathrm{Se}$ previously observed in MTM-impacted streams. ${ }^{15}$ The study was conducted in the Mud River watershed in Lincoln and Boone Counties of West Virginia (Figure 1) and was based on two components. The first was systematic measurements of the chemical composition and $\delta^{13} \mathrm{C}_{\mathrm{DIC}}, \delta^{34} \mathrm{~S}_{\mathrm{SO} 4}$, and ${ }^{87} \mathrm{Sr} /{ }^{86} \mathrm{Sr}$ in surface water streams and tributaries originated from MTM sites. On the basis if their spatial distribution, we divided the sample locations into four subcategories including tributaries draining both active and reclaimed sections of MTM operations as well as the upstream and downstream sections (with respect to MTM drainage areas) of the main stem of the Mud River (Figure 1). A second component of the study was measurements of major elements, selenium, and ${ }^{87} \mathrm{Sr} /{ }^{86} \mathrm{Sr}$ in leachates of rocks of the lower section of the Allegheny Formation and the upper section of the Kanawha Formation collected from a 70 meter core drilled in the Hobet 21 mine in West Virginia
(Figure 1 and Figures S1 and S2 and Table S1, Supporting Informaiton ${ }^{20}$ ). The objective of this study is to determine whether MTM effluents have distinctive stable isotopic imprints relative to unaffected stream waters and to test their application as diagnostic tools for tracing the impact of MTM effluents on stream chemistry and ecology in the Appalachian Basin.

\section{METHODS}

Water samples were collected monthly from May to December 2010 from 23 locations on the main stem of the Mud River and its tributaries in West Virginia (Figure 1). Water sampling strictly followed U.S. Geological Survey (USGS) protocol. ${ }^{32}$ Samples for metals and major ions were filtered with a $0.45 \mu \mathrm{m}$ syringe disk filter. Dissolved metal samples were preserved with $0.2 \% \mathrm{v} / \mathrm{v}$ trace metal grade nitric acid with all sample bottles placed on ice prior to storage at $4.0^{\circ} \mathrm{C}$ in the laboratory. Trace elements were measured with a VG PlasmaQuad-3 (Thermo Fisher Scientific, Inc.) inductively coupled plasma mass spectrometer (ICP-MS) and major elements with an ARL SpectraSpan 7 (Thermo Fisher Scientific, Inc.) direct current plasma optical emission spectrometer (DCP-OES) and ion chromatography (IC) at Duke University. The detection limit of Se $(1.1 \mathrm{ppb})$ was determined by dividing three times the standard deviation of repeated blank measurements by the slope of the external standard. Analytical precision for Se (5\%) was calculated as the relative percent difference (RPD) of the results of duplicate sample measurements.

Strontium isotopes were analyzed by thermal ionization mass spectrometry (TIMS) on a ThermoFisher Triton at the TIMS 
Table 1. Mean Values of Water Quality and Isotopic Tracers of Water Samples Collected from the Upstream Section of the Mud River, Downstream of the Mud River, Tributaries from Reclaimed MTM Areas, and Tributaries from Active MTM Areas ${ }^{a}$

\begin{tabular}{|c|c|c|c|c|c|c|c|c|c|c|c|}
\hline & EC & $\mathrm{pH}$ & $\mathrm{Ca}(\mathrm{ppm})$ & $\mathrm{Mg}(\mathrm{ppm})$ & $\mathrm{SO}_{4}(\mathrm{ppm})$ & Se $(p p b)$ & $\mathrm{Sr}(\mathrm{ppb})$ & $\mathrm{Sr} / \mathrm{Ca}$ & ${ }^{87} \mathrm{Sr} /{ }^{86} \mathrm{Sr}$ & $\delta^{34} S$ & $\delta^{13} \mathrm{C}-\mathrm{DIC}$ \\
\hline \multicolumn{12}{|l|}{ Mud River watershed } \\
\hline upstream Mud River & 155 & 7.1 & 13.7 & 5.7 & 34.3 & BDL & 78.9 & 0.0057 & 0.71426 & 3.91 & -6.9 \\
\hline downstream Mud River & 1291 & 7.3 & 118 & 95 & 653 & 8.4 & 710 & 0.0061 & 0.71487 & 0.4 & -1.1 \\
\hline tributaries from reclaimed MTM & 1512 & 7.8 & 129 & 126 & 856 & 3.5 & 391 & 0.0032 & 0.71703 & 0.1 & -1.3 \\
\hline tributaries from active MTM & 1369 & 7.1 & 132 & 84 & 657 & 15.5 & 1235 & 0.0089 & 0.71452 & 0.3 & -0.2 \\
\hline \multicolumn{12}{|l|}{ Rock leaching } \\
\hline Alleghenny Fm., combined & 709 & 3.8 & 140 & 48 & 1882 & 683 & 568 & 0.0047 & 0.71611 & - & - \\
\hline Alleghenny Fm., noncoal & 260 & 4.5 & 144 & 61 & 774 & 809 & 413 & 0.0032 & 0.71830 & - & - \\
\hline Alleghenny Fm., coal & 1249 & 2.9 & 132 & 23 & 2712 & 454 & 852 & 0.0075 & 0.71265 & - & - \\
\hline Kanawha Fm., combined & 994 & 3.9 & 277 & 113 & 1605 & 348 & 6458 & 0.0247 & 0.71342 & - & - \\
\hline Kanawha Fm., noncoal & 768 & 4.4 & 321 & 143 & 1455 & 430 & 7769 & 0.0259 & 0.71409 & - & - \\
\hline Kanawha Fm., coal & 1252 & 3 & 213 & 72 & 1755 & 220 & 4623 & 0.0233 & 0.71262 & - & - \\
\hline
\end{tabular}

${ }^{a}$ These variations are compared to mean values measured in water-soluble salts extracted from rocks (see lithology information in Table S1, Supporting Information) as part of leaching experiments in this study. The rock samples from the Allegheny and Kanawha Formations represent the surface geology in the area of the Hobet \#21 mine.

lab at Duke University. The average ${ }^{87} \mathrm{Sr} /{ }^{86} \mathrm{Sr}$ of the SRM-987 standard measured during this study was $0.710266 \pm 0.000005$ (SD). The carbon isotope ratio of dissolved inorganic carbon was analyzed by acid digestion on a ThermoFinnigan GasBench II, feeding a ThermoFinnigan Delta+XL isotope ratio mass spectrometer (IRMS) at Duke University. The $\delta^{13} \mathrm{C}$ of the resulting $\mathrm{CO}_{2}$ was normalized vs Vienna Pee Dee Belemnite (VPDB) using NBS19, IAEA CO-8 standards, and an internal $\mathrm{CaCO}_{3}$ standard and were expressed as $\delta^{13} \mathrm{C}_{\text {DIC }}$. Sulfur isotopes were measured in a continuous-flow gas-ratio mass spectrometer (ThermoQuest Finnigan Delta PlusXL) at the Environmental Isotope Laboratory at the University of Arizona. The system was calibrated by using international standards OGS-1 and NBS123. Precision was estimated to be $\pm 0.15 \%$. The ${ }^{34} \mathrm{~S} /{ }^{32} \mathrm{~S}$ ratio was normalized to the standard VCDT (Vienna Canyon Diablo Troilite) and expressed as $\delta^{34} \mathrm{~S}_{\mathrm{SO} 4}$.

Surface geology was examined through leaching experiments of powder-crushed rocks from a core collected from the Hobet 21 mine (457 m north of the Hobet 21 main office, between Bragg Fork and the right fork of Long Branch, Scott District; latitude, 38.11900; longitude, 81.87806) in Boone County, West Virginia (Figure 1 and Figure S2, Supporting Information). The $70 \mathrm{~m}$ core (depth interval of 40 to 110 $\mathrm{m}$ ) was composed of coal and noncoal rocks from the Middle Pennsylvanian Allegheny and Kanawha formations (Figure S2, Table S1, Supporting Information ${ }^{20}$ ). Four to five grams of each powdered rock sample was combined with $40-50 \mathrm{~mL}$ of deionized water ( $>18 \mathrm{M} \Omega$ s; liquid to solid ratio of $\sim 10$ ) in a HDPE trace-metal free centrifuge tube. The combined samples were shaken for $24 \mathrm{~h}$ and then removed from the shaker. The samples were centrifuged; the liquid was then decanted and filtered through $0.45 \mu \mathrm{m}$ filters into new $50 \mathrm{~mL}$ HDPE tracemetal free centrifuge tubes. The control samples followed this same procedure only with deionized water and no rock sample. Leachates were measured for $\mathrm{pH}$, electric conductivity, major ions, $\mathrm{Se}$, and strontium isotope ratios.

\section{RESULTS AND DISCUSSION}

Geochemical and Isotopic Characterization of VF Effluents. The major dissolved constituents in tributaries of the Mud River (Figure 1) that determine the overall salinity were $\mathrm{Ca}, \mathrm{SO}_{4}$, and DIC (Figure S3, Supporting Information). On the basis of systematic sampling of tributaries originating from VFs in the watershed of the Mud River, ${ }^{15}$ we define two types of tributaries: those originated from areas draining VFs of active and current MTM activities and those from nonactive reclaimed MTM areas (Figure 1). The definition of MTM refers to the timing of operation; reclaimed areas are MTM operations of mostly, but not exclusively, of coal from the overlying Allegheny Formation in the eastern part of the Mud River watershed. Active MTM refers to current MTM activities of mostly the deeper Kanawha Formation in the central and western section of the watershed (Figure 1 and Figure S1, Supporting Information). Our data show that both types of tributaries are characterized by relatively high salinity and sulfate concentrations but differ with higher concentrations of $\mathrm{Sr}$ and Se observed in tributaries draining active MTM (Table 1 , Figures 2 and 3 ). Additionally, sulfate, $\delta^{34} S_{\mathrm{SO} 4}$, DIC, and $\delta^{13} \mathrm{C}_{\text {DIC }}$ variations are indistinguishable between tributaries originated from active and reclaimed MTM areas (Figure S4, Supporting Information) but differ in their $\mathrm{Sr} / \mathrm{Ca}$ and ${ }^{87} \mathrm{Sr} /{ }^{86} \mathrm{Sr}$ (Table 1, Figures 2, 3, and Figure S1, Supporting Information).

The variations of $\delta^{13} \mathrm{C}_{\mathrm{DIC}}$ and $\delta^{34} \mathrm{~S}_{\mathrm{SO} 4}$ (Figures 4, 5) indicate that DIC and $\mathrm{SO}_{4}$ were derived from two major sources: (1) diluted tributaries depleted in ${ }^{13} \mathrm{C}_{\mathrm{DIC}}\left(\delta^{13} \mathrm{C}_{\mathrm{DIC}}<-6 \% 0\right)$ and slightly enriched in ${ }^{34} \mathrm{~S}_{\mathrm{SO} 4}\left(\delta^{34} \mathrm{~S}_{\mathrm{SO} 4}>+5 \%\right)$ and (2) saline tributaries enriched in ${ }^{13} \mathrm{C}_{\mathrm{DIC}}\left(\delta^{13} \mathrm{C}_{\mathrm{DIC}} \sim+6 \%\right.$ ) and slightly depleted $\mathrm{in}^{34} \mathrm{~S}_{\mathrm{SO} 4}\left(\delta^{34} \mathrm{~S}_{\mathrm{SO} 4}=-2\right.$ to $+2 \%$ ). The respectively low $\delta^{13} \mathrm{C}_{\mathrm{DIC}}$ and high $\delta^{34} \mathrm{~S}_{\mathrm{SO} 4}$ of the diluted tributaries mimic the natural background conditions (soil processes and meteoric sulfate) and were also observed in the upstream section of the Mud River without any mining influence, prior to the river flow through the MTM affected area. In contrast, we suggest that the high $\delta^{13} \mathrm{C}_{\mathrm{DIC}}$ and low $\delta^{34} \mathrm{~S}_{\mathrm{SO} 4}$ in the saline tributaries reflect the composition of the source DIC and sulfate in VFs. The positive $\delta^{13} \mathrm{C}_{\mathrm{DIC}}$ signature of the DIC-enriched tributaries is substantially different from the negative carbon isotope composition typical to the Appalachian coal $\left(\delta^{13} \mathrm{C}\right.$ range of -22 to -27 $\left.\%{ }^{28,29}\right)$. The positive $\delta^{13} \mathrm{C}_{\mathrm{DIC}}$ also differed from measurements of total soil samples for MTM reclaimed soils, forest soils, and grassland soils that all yielded low $\delta^{13} \mathrm{C}(-25$ to $\left.-28 \%{ }^{33}\right)$. The high $\delta^{13} \mathrm{C}_{\mathrm{DIC}}$ signature is also different from the composition that characterizes natural waters (a range of $-21 \%$ to $-10 \%$ ) in which DIC dissociation and carbonate dissolution are derived from carbonic acid originated from organic matter oxidation and ${ }^{13} \mathrm{C}$-depleted $\mathrm{CO}_{2} \cdot{ }^{34}$ In contrast, 

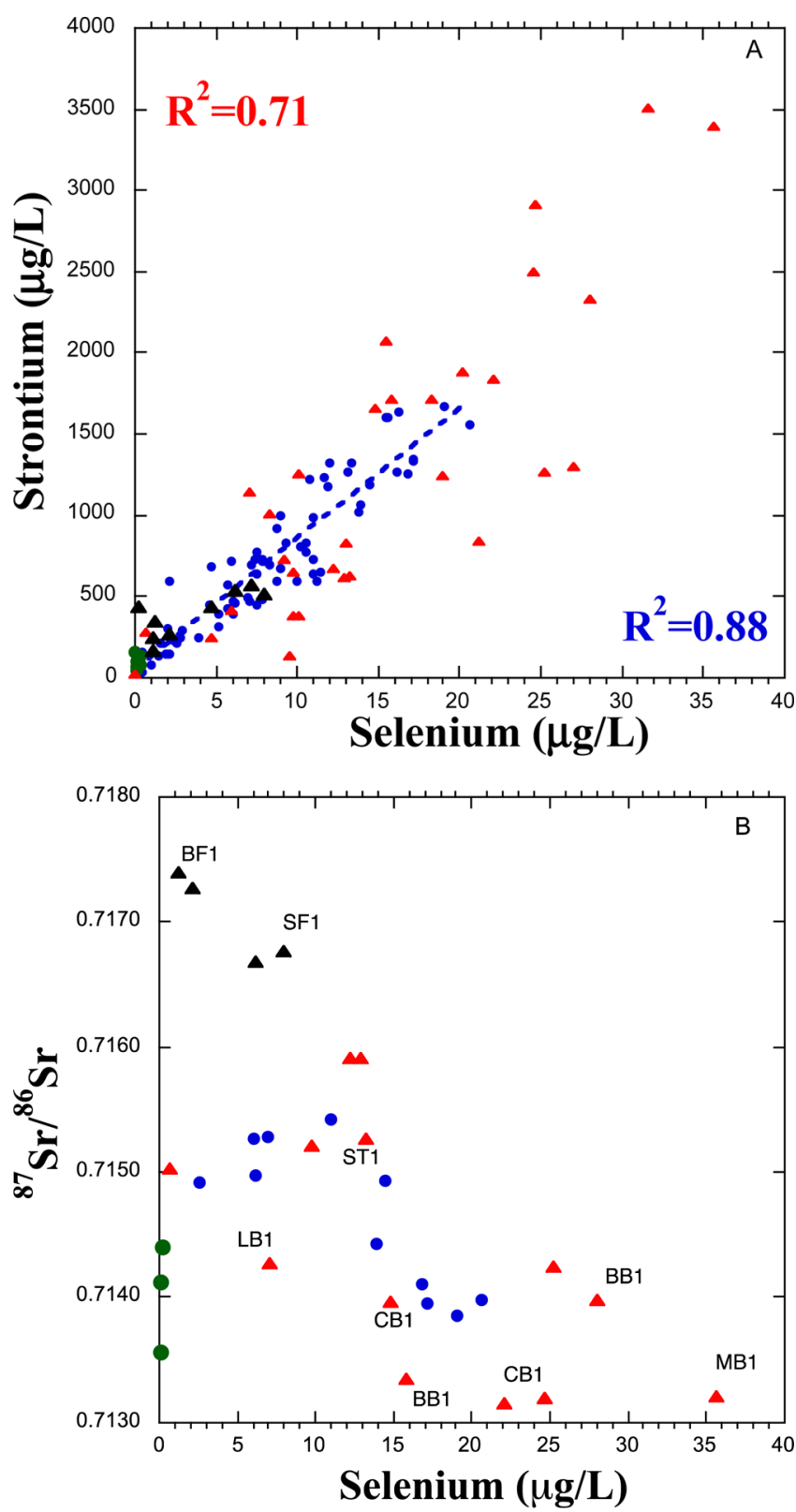

Figure 2. (A) Strontium versus selenium concentrations and (B) ${ }^{87} \mathrm{Sr} /{ }^{86} \mathrm{Sr}$ versus selenium concentrations in tributaries draining reclaimed MTM areas (black triangles), active mines (red triangles), upstream section of the Mud River (green circles), and downstream of the Mud River (blue circles). See sample locations in Figure 1. Note the linear correlation between $\mathrm{Se}$ and $\mathrm{Sr}$ and the inverse correlation between ${ }^{87} \mathrm{Sr} /{ }^{86} \mathrm{Sr}$ and selenium.

relatively positive $\delta^{13} \mathrm{C}_{\mathrm{DIC}}$ values (a range of $-10 \%$ to $+0.8 \%$ ) were measured in acid mine drainage (AMD) from Pennsylvania that was attributed to dissolution of carbonate minerals by sulfuric acid originated from pyrite oxidation. ${ }^{31}$ The high $\delta^{13} \mathrm{C}$ composition (a range of 2 to $5 \%$ ) is typical for Pennsylvanian marine carbonate rocks, ${ }^{35}$ which is equivalent to the Allegheny and Kanawha Formations. These values are consistent with the $\delta^{13} \mathrm{C}_{\mathrm{DIC}}$ values of the apparent high DIC end member presented in Figure 5.

Our leaching experiments (see below) demonstrate that indeed pyrite oxidation generates sulfuric acid that apparently dissolves calcium carbonate in VFs. We conclude that the bulk DIC in effluents derived from VF is derived from dissolution of

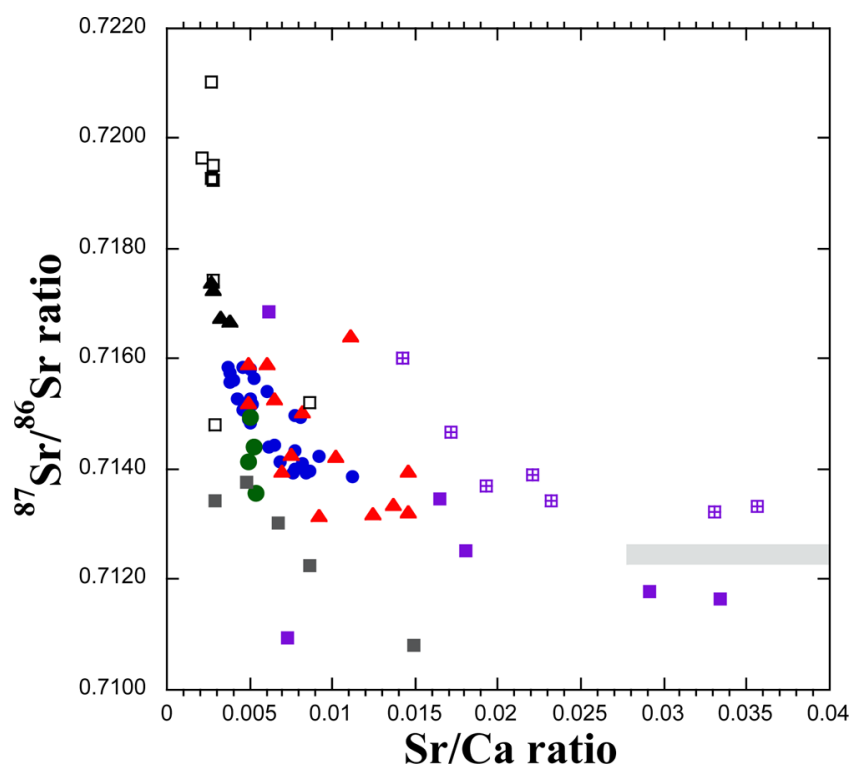

Figure 3. ${ }^{87} \mathrm{Sr} /{ }^{86} \mathrm{Sr}$ versus $\mathrm{Sr} / \mathrm{Ca}$ ratios in tributaries from reclaimed MTM areas (black triangles), active mines (red triangles), upstream section of the Mud River (green circles), and downstream of the Mud River (blue circles) as compared to water-soluble fractions from leaching of coal rocks (gray squares) and noncoal rocks (open black squares) from the shallow Allegheny Formation and coal rocks (purple squares) and noncoal rocks (purple checkers) from the deeper Kanawha Formation. Note that leachates from coal-containing rocks from both formations and noncoal rocks from the Kanawha Formation had typically lower ${ }^{87} \mathrm{Sr} /{ }^{86} \mathrm{Sr}$, similar to tributaries from active mines VFs with high $\mathrm{Sr} / \mathrm{Ca}$ and lower ${ }^{87} \mathrm{Sr} /{ }^{86} \mathrm{Sr}$. This ${ }^{87} \mathrm{Sr} /{ }^{86} \mathrm{Sr}$ ratio $(\sim 0.7124)$ seems to represent a common soluble strontium isotopic imprint for Appalachian coals (marked as gray area).

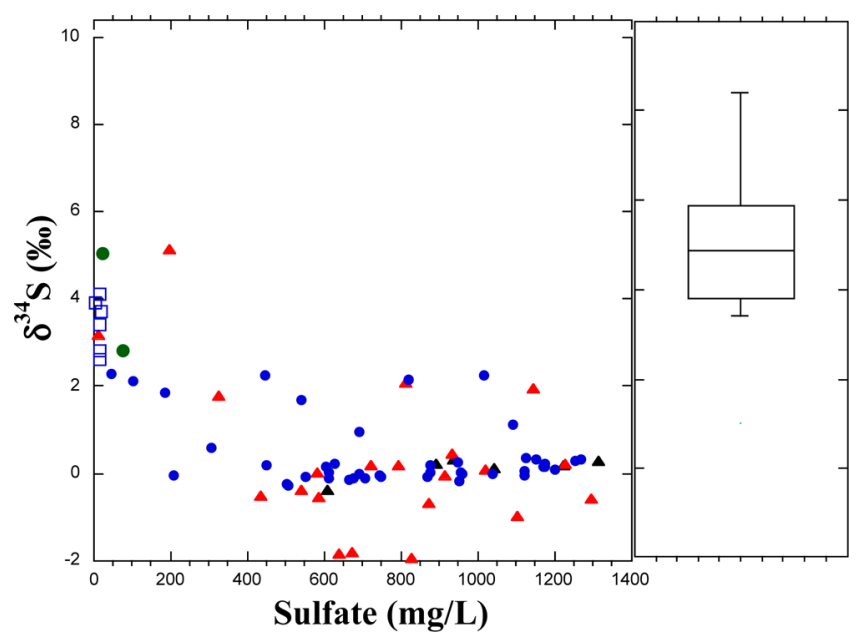

Figure 4. $\delta^{34} \mathrm{~S}$ (normalized to Vienna Canyon Diablo Troilite) versus sulfate concentrations in tributaries from reclaimed MTM areas (black triangles), active mines (red triangles), upstream section of the Mud River (green circles), and downstream of the Mud River (blue circles) as compared to uncontaminated streams from West Virginia (open blue square ${ }^{36}$ ). On the right panel is the distribution of $\delta^{34} S$ in typical meteoric water. ${ }^{37}$ Note that waters with low sulfate contents from the upper section of the Mud River and tributaries had higher $\delta^{34} S$, which is consistent with previous reports for $\delta^{34} S$ in meteoric water. In contrast, the sulfate-rich waters had a lower $\delta^{34} \mathrm{~S}$ signature.

inorganic carbonates with a positive $\delta^{13} \mathrm{C}$ imprint due to sulfuric acid originated from pyrite oxidation. The linear 


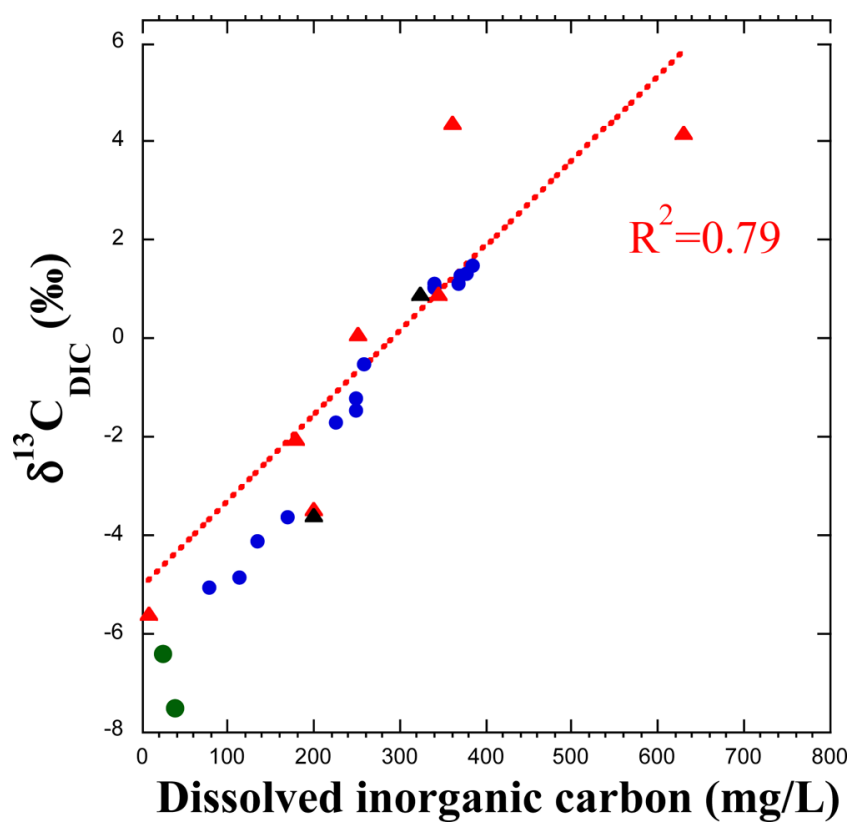

Figure 5. $\delta^{13} \mathrm{C}$ (normalized to Vienna Pee Dee Belemnite) versus dissolved inorganic carbon (DIC) concentrations in tributaries from reclaimed MTM areas (black triangles), active mines (red triangles), upstream section of the Mud River (green circles), and downstream of the Mud River (blue circles). Note the linear correlation that reflects a conservative mixing between low DIC with depleted $\delta^{13} \mathrm{C}$ and high DIC with high $\delta^{13} \mathrm{C}$.

correlation between DIC and $\delta^{13} \mathrm{C}_{\text {DIC }}$ in Figure 5 therefore reflects a mixing between two DIC sources: (1) organic carbon in soil that generates ${ }^{13} \mathrm{C}$-depleted $\mathrm{CO}_{2}$ that is indicative of pristine natural waters with low DIC and (2) dissolution of carbonates in the residual rock materials in VFs with a positive $\delta^{13} \mathrm{C}(>+6 \%$ ) .

Likewise, we attribute the slightly elevated $\delta^{34} \mathrm{~S}_{\mathrm{SO} 4}(\sim+5 \%$ o $)$ in the diluted tributaries to a meteoric source, which is consistent with the $\delta^{34} \mathrm{~S}_{\mathrm{SO} 4}$ of bulk precipitation and pristine stream waters in the upland forested catchments within the Appalachian Plateau region of West Virginia ${ }^{36}$ and other inland basins (Figure 4) ${ }^{37}$ In contrast, the saline tributaries with high $\mathrm{SO}_{4}$ had lower $\delta^{34} \mathrm{~S}_{\mathrm{SO} 4}(-2$ to $+2 \%$ ) , originated from oxidation of pyrite from within the bedrock, which typically has a similar low $\delta^{34} S$ range. ${ }^{37}$ These results are also consistent with an elevated $\mathrm{SO}_{4}$ and an apparent $\delta^{34} \mathrm{~S}$ end member of $\sim 1 \%$ o measured in stream waters of Yellow Creek, West Virginia, also associated with coal mining. ${ }^{36}$

Impact on the Mud River. The chemical and isotopic variations of the mining-impacted tributaries are notably different from those of the upper Mud River, above any current mining activity (Table 1 and Figure 1). Data demonstrating the gradual and accumulative increase of salinity (Figure S5, Supporting Information), sulfate, Sr, and Se contents with higher intensity of MTM were reported previously. ${ }^{15}$ The dilute upstream section of river is characterized by low $\delta^{13} \mathrm{C}_{\mathrm{DIC}}$ and high $\delta^{34} \mathrm{~S}_{\mathrm{SO} 4}$ that are distinguished from the composition of the downstream section of the Mud River (Figures S7, S8, Supporting Information). Temporal variations in salinity (Figure S5, Supporting Information), sulfate, bicarbonate, selenium, and strontium concentrations showed seasonal fluctuations in the Mud River, resulting from dilution. Yet, the increase in $\delta^{13} \mathrm{C}_{\mathrm{DIC}}$ and the decrease in $\delta^{34} \mathrm{~S}_{\mathrm{SO} 4}$ and ${ }^{87} \mathrm{Sr} /{ }^{86} \mathrm{Sr}$ (Figures S6, S7, S8, Supporting Information) in the downstream river clearly reflect the effect of the tributaries' inflows, regardless of their absolute concentrations. The ${ }^{87} \mathrm{Sr} /{ }^{86} \mathrm{Sr}$ ratios of tributaries that drain reclaimed mining areas are different from those draining current MTM watersheds. This ratio fluctuates as the river flows downstream depending on the mining status of the contributing watershed (Figure S6, Supporting Information); river waters downstream from tributaries from reclaimed and active VFs are characterized by relatively high and low ${ }^{87} \mathrm{Sr} /{ }^{86} \mathrm{Sr}$ ratios, respectively (Figure 6 and Figure S6, Supporting

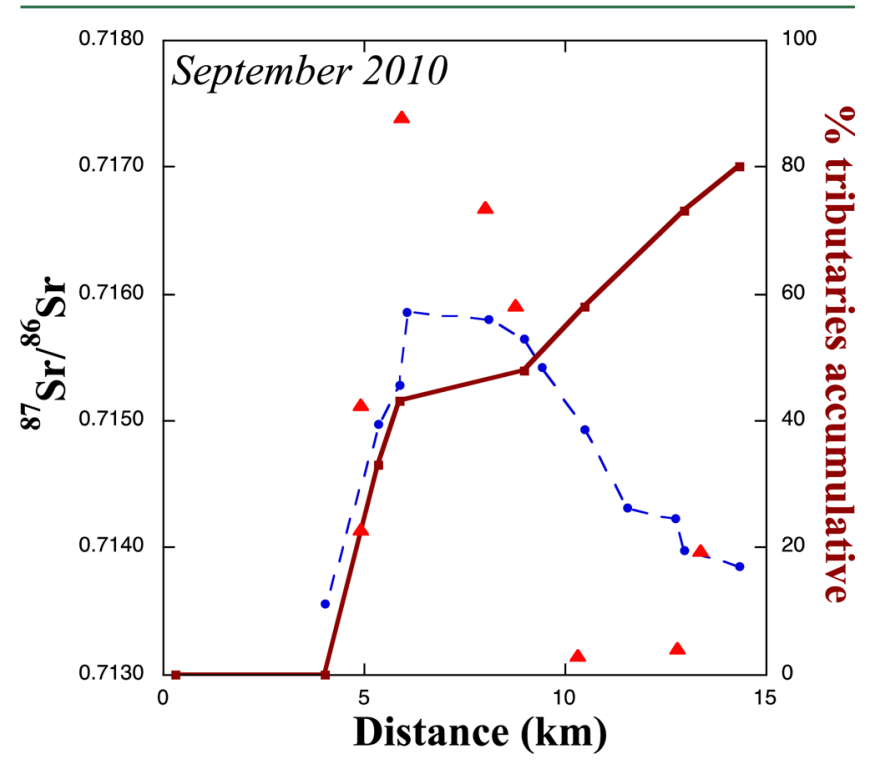

Figure 6. Variations of ${ }^{87} \mathrm{Sr} /{ }^{86} \mathrm{Sr}$ in the Mud River (blue circles) and calculated accumulated contribution of the external tributaries (red line, see calculations in Table 1) during September 2010 sampling as compared to the ${ }^{87} \mathrm{Sr} /{ }^{86} \mathrm{Sr}$ ratios of tributaries (red triangles) along the Mud River flow. Distance $(\mathrm{km})$ refers to the flow of the Mud River from the initial sample (Figure 1). Note that the changes in the ${ }^{87} \mathrm{Sr} /{ }^{86} \mathrm{Sr}$ of the tributary inflows modify the ${ }^{87} \mathrm{Sr} /{ }^{86} \mathrm{Sr}$ in river water in downstream samples.

Information). The preservation of the chemical and isotopic variations in the downstream Mud River (e.g., the linear correlation between $\mathrm{Sr}$ and Se; Figure 3A) indicates that the major and minor constituents, including selenium, behave conservatively in the river system without retention or attenuation. These results are consistent with earlier observations that the salinity, sulfate, and Se concentrations in MTM streams are linearly proportional to the extent of surface mining in the watershed. ${ }^{14,15}$

A mass-balance calculation, using the $\mathrm{Sr}$ and ${ }^{87} \mathrm{Sr} /{ }^{86} \mathrm{Sr}$ in a mixing model, provides a sensitive evaluation of the fraction of the tributaries contributing to each of the downstream sampling points along the Mud River (Figure 1). We estimate that the tributaries provide between $5 \%$ and $33 \%$ of the dissolved constituents in the mainstem at different sampling locations along its flow (Figure 1 and Table S3, Supporting Information). The rise of $\mathrm{Sr}$ concentrations in the Mud River from $95 \mu \mathrm{g} / \mathrm{L}$ in the nonimpacted section (MR-2) to $1672 \mu \mathrm{g} / \mathrm{L}$ in the downstream site (MR-11), about $10 \mathrm{~km}$ downstream from the first MTM tributary that enters the Mud River, corresponds to an overall $80 \%$ accumulative input of dissolved $\mathrm{Sr}$ from MTM tributaries (Figure 6). 

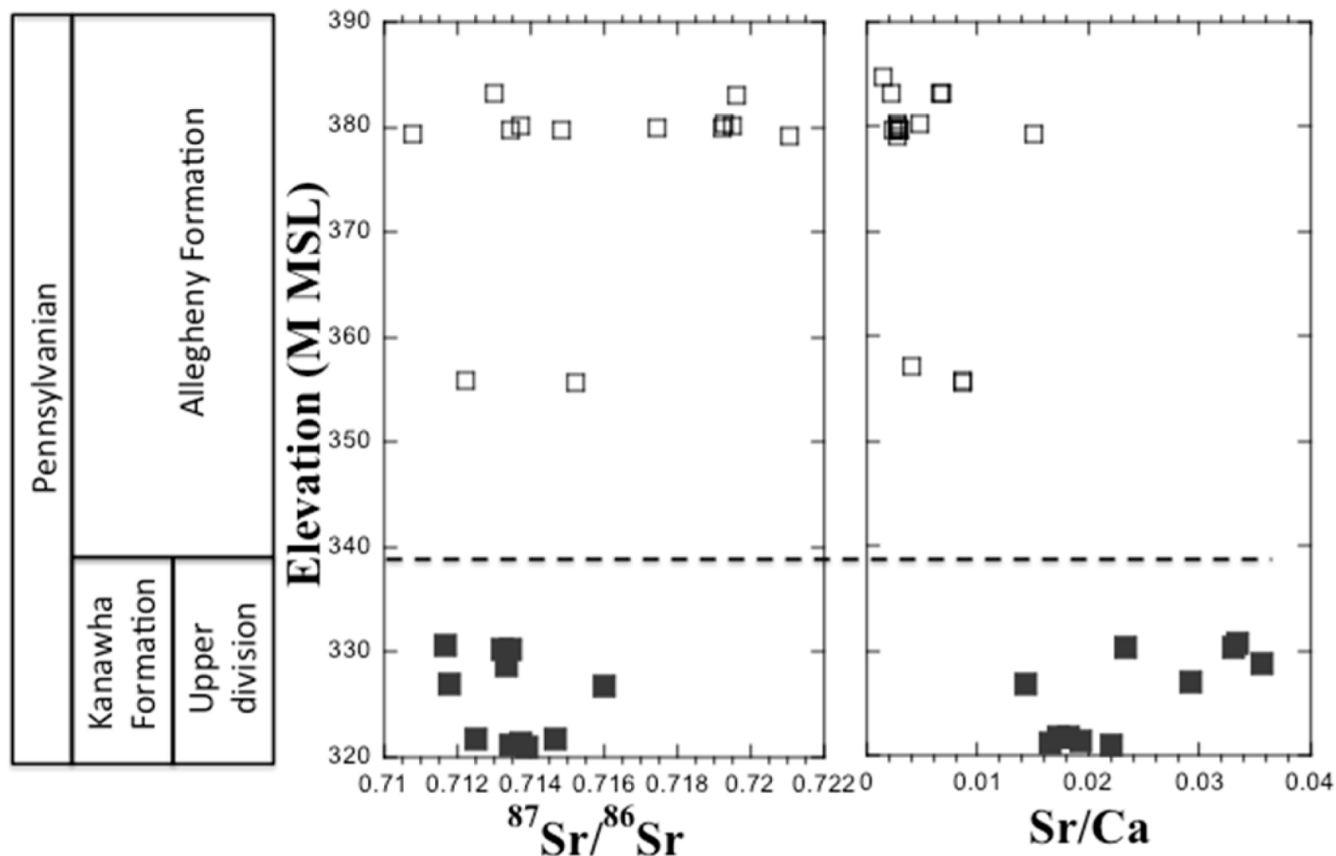

Figure 7. Variations of water-soluble ${ }^{87} \mathrm{Sr} /{ }^{86} \mathrm{Sr}$ and $\mathrm{Sr} / \mathrm{Ca}$ in leachates from rocks of the Allegheny and Kanawha Formations, revealed by a $70 \mathrm{~m}$ core from Hobet \#21. ${ }^{20}$ Note the wide range of ${ }^{87} \mathrm{Sr} /{ }^{86} \mathrm{Sr}$ and lower $\mathrm{Sr} / \mathrm{Ca}$ ratios in water-soluble salts extracted from the upper Allegheny Formation relative to lower ${ }^{87} \mathrm{Sr} /{ }^{86} \mathrm{Sr}$ and higher $\mathrm{Sr} / \mathrm{Ca}$ in the lower Kanawha Formation.

Leaching Experiments of Local Bedrock from the Hobet \#21 Mine. The lower and upper sections of the Middle Pennsylvanian Allegheny and Kanawha Formations represent the surface geology within the permitted area of the Hobet \#21 mine ${ }^{19-21}$ (Figure 7 and Figures S1, S2, Table S1, Supporting Information). In order to characterize the chemistry and ${ }^{87} \mathrm{Sr} /{ }^{86} \mathrm{Sr}$ variations of soluble salts that are mobilized from the watershed rocks, we conducted leaching experiments on rocks obtained from a core sample of the Allegheny and Kanawha Formations (Table S1, Figure S2, Supporting Information). Our data show that the salinity (as expressed as EC) of the water-soluble salts in rocks from the Allegheny and Kanawha Formations is high (Table 1), similar to the field EC values measured in VF effluents, and inversely correlated with the leachates' pH (Figure S9, Supporting Information). On the basis of our leaching experiments, we suggest that the oxidation of pyrite, which evidently exists in all rock types from the Allegheny and Kanawha Formations (Figure S9, Supporting Information), generates both elevated sulfate (Figure S10, Supporting Information) and acidity. Yet, calcium variations were not correlated directly with the total salinity (i.e., EC) relative to sulfate (Figures S10, S11, Supporting Information). This suggests that calcium was derived by dissolution of calcium carbonate minerals. We observed that leachates from rocks containing coal tend to generate higher sulfate (and acidity), while leachates from noncoal rocks have higher calcium, magnesium, and strontium contents (Table 1). These results are consistent with the overall high soluble TDS reported for leaching experiments of MTM overburden spoils and coarse/fine coal refuse. ${ }^{38}$ The inverse correlation between EC (and sulfate) and $\mathrm{pH}$ (Figures S9, S10, Supporting Information) confirms that sulfuric acid generated during the oxidation of pyrite is responsible for dissolution of the carbonate minerals in VFs and not from carbonic acid that originated from the oxidation of organic matter in the soil. This is further verified by the elevated $\delta^{13} \mathrm{C}_{\mathrm{DIC}}$ values measured in VF effluents (Figure 5).

In contrast, soluble strontium and ${ }^{87} \mathrm{Sr} /{ }^{86} \mathrm{Sr}$ were different in leachates from the rocks representing the two formations, with significantly lower strontium in the shallower Allegheny Fomation (mean $=567 \pm 400 \mathrm{ppb}, n=17)$ relative to the deeper Kanawha Formation $($ mean $=6458 \pm 4919 \mathrm{ppb}, n=12)$ (Table 1). Likewise, the ${ }^{87} \mathrm{Sr} /{ }^{86} \mathrm{Sr}$ ratio in the Allegheny Formation (mean $=0.71611 \pm 0.00338, n=13$ ) was higher than that of the Kanawha Formation (mean $=0.71342 \pm$ $0.00124, n=11$ ) (Figure 7). The leaching experiments reveal therefore two distinctive soluble rock sources: (1) low $\mathrm{Sr} / \mathrm{Ca}$ and high ${ }^{87} \mathrm{Sr} /{ }^{86} \mathrm{Sr}$ in the shallow rocks of the Allegheny Formation and (2) high $\mathrm{Sr} / \mathrm{Ca}$ and low ${ }^{87} \mathrm{Sr} /{ }^{86} \mathrm{Sr}$ in the deeper rocks of the Kanawha Formation. It should be noted that the ${ }^{87} \mathrm{Sr} /{ }^{86} \mathrm{Sr}$ ratios of rock samples containing coal were almost identical in both the Allegheny and Kanawha Formations $\left(\sim 0.7126\right.$, Table 1). Similar ${ }^{87} \mathrm{Sr} /{ }^{86} \mathrm{Sr}$ ratios were also reported in coal impoundments from the West Virginia $(0.7124)^{25}$ and Pittsburgh coal $(0.71168),{ }^{31}$ which seem to represent a common soluble strontium isotopic imprint for the Appalachian coals (Figure 3). In contrast, the ${ }^{87} \mathrm{Sr} /{ }^{86} \mathrm{Sr}$ ratios in leachates from noncoal rocks from both formations were different, with higher ratios in the shallow Allegheny Formation (0.71830) relative to the deeper Kanawha Formation (0.71409, Table 1).

While we observed differences in $\mathrm{Sr} / \mathrm{Ca}$ and ${ }^{87} \mathrm{Sr} /{ }^{86} \mathrm{Sr}$ ratios in leachates from the different formations, the Se concentrations were indistinguishable (Table 1). Nonetheless, we show that Se concentration in leachates increases with higher $\mathrm{Ca} / \mathrm{EC}$ ratio (Figure S7, Supporting Information). A high Ca/ EC ratio reflects a larger $\mathrm{Ca}$ contribution fraction from carbonate dissolution (i.e., high $\mathrm{Ca} / \mathrm{EC}$ ) relative to the contribution of $\mathrm{SO}_{4}$ that is generated from pyrite oxidation (i.e., low $\mathrm{Ca} / \mathrm{EC}$ ). Thus, the leaching experiments suggest that Se mobilization is associated with carbonate dissolution and not 
pyrite oxidation in both the Allegheny and Kanawha Formations. This conclusion is consistent with the high correlations observed between $\mathrm{Se}$ and $\mathrm{Sr}$ in the tributaries (Figure 2) that seem to reflect a common carbonate source for both $\mathrm{Sr}$ and Se in VF effluents. This is also consistent with the observations of Vesper et al., ${ }^{21}$ who showed that Se abundance is not associated with sulfur content in the rocks of Kanawha Formation and $\mathrm{Se}$ is distributed in both coal and noncoal rocks. $^{21}$

The inverse relationship of $\mathrm{Sr} / \mathrm{Ca}$ and ${ }^{87} \mathrm{Sr} /{ }^{86} \mathrm{Sr}$ observed in the rock leaching experiments overlap with the variations observed in the MTM tributaries, particularly the distinction between tributaries draining active (high $\mathrm{Sr} / \mathrm{Ca}$ and low ${ }^{87} \mathrm{Sr} /{ }^{86} \mathrm{Sr}$ ) and reclaimed MTM sites (low $\mathrm{Sr} / \mathrm{Ca}$ and high ${ }^{87} \mathrm{Sr} /{ }^{86} \mathrm{Sr}$, Figure 3). In contrast, the bulk salt concentrations of ions such as $\mathrm{Ca}$ and $\mathrm{SO}_{4}$ were indistinguishable in tributaries from active and reclaimed MTM areas. This is consistent with the uniformly high soluble salt concentrations found in leachates from both the Allegheny and Kanawha Formations (Table 1). Given the overlap of these geochemical trends (Figure 3), we propose that the low $\mathrm{Sr} / \mathrm{Ca}$ and high ${ }^{87} \mathrm{Sr} /{ }^{86} \mathrm{Sr}$ signatures of the reclaimed MTM tributaries reflect past mining of the predominantly shallow coal seams of the Allegheny Formation, while more recent and active mining incorporates a deeper section of the geological strata, including the Kanawha Formation with its distinctive $\mathrm{Sr} / \mathrm{Ca}$ and ${ }^{87} \mathrm{Sr} /{ }^{86} \mathrm{Sr}$ signatures. Because these geological materials are mixed in the VFs, one would expect that the effluents that are generated by interactions of the blended rock materials would contain the geochemical fingerprints of the most abundant rock materials. It seems, therefore, that modern forms of MTM surface mining have been more effective in targeting and extracting the deeper coal seams (e.g., Stockton) of the Kanawha Formation (Figure S2, Supporting Information).

The increased contribution of the deeper coal seams is also reflected by current coal production statistics, showing the increased exploitation of coals associated with the Kanawha Formation over time. ${ }^{19}$ Historic data show that between 1983 and 1997 coal production from the Kanawha Formation doubled from about 40 million tons to over 80 million tons, while coal production from the overlying Allegheny Formation was not changed and remained below 40 million tons. ${ }^{19}$ The high correlation between $\mathrm{Sr}$ and Se observed in the tributaries ${ }^{15}$ (Figure 2) suggests that the deeper rocks of the Kanawha Formation also have higher Se contents. This is consistent with the high Se contents reported for noncoal rocks of the Kanawha Formation in Boone County, West Virginia. ${ }^{21}$ However, our leaching experiments did not show higher selenium concentrations in water-soluble leachates from the Kanawha Formation (Table 1). These results are probably due to the difference on water chemistry; the Se-rich VF effluents are characterized by a neutral to high $(6-8) \mathrm{pH}$, while the water-soluble leachates from the laboratory experiments were much more acidic (Table 1). Given that selenium mobilization is expected to intensify under elevated $\mathrm{pH}$ conditions, ${ }^{39}$ we posit that the generation of sulfuric acid from pyrite oxidation would trigger carbonate dissolution, which would buffer the $\mathrm{pH}$ of VF effluents and further enhance selenium mobilization from the carbonate phases. We conclude that the geochemical and isotopic changes we observed in leachates from rocks spanning the transition from Allegheny to Kanawha Formations are representative of the expected composition of the blended rock found in VFs and the resulting chemical influence they have on the headwaters flowing to the Mud River.

This study reveals distinct geochemical fingerprints of $\delta^{34} \mathrm{~S}_{\mathrm{SO} 4}, \quad \delta^{13} \mathrm{C}_{\mathrm{DIC}}, \mathrm{Sr} / \mathrm{Ca}$, and ${ }^{87} \mathrm{Sr} /{ }^{86} \mathrm{Sr}$ in MTM effluents compared to those of the unimpacted and upper section of the Mud River, representing a typical Appalachian watershed. The changes in water quality in the downstream section of the river, in particular the increase in salinity, $\mathrm{SO}_{4}$, and $\mathrm{Se}$, are directly associated with isotopic modifications of DIC, sulfate, and strontium, reflecting the cumulative effect of the dissolved constituents derived from VF effluents. Given the linear correlation between $\mathrm{Se}$ and $\mathrm{Sr}$, we posit that $\mathrm{Sr}$ isotopes can be used as a valuable geochemical proxy for tracing Se origin and mobilization in impacted Appalachian watersheds. In particular, one can apply the Sr isotope tool for quantification of dilution (i.e., with no change in isotopic ratio) versus mixing of different sources for evaluating the processes that control Se occurrence in contaminated water sources. A mixing model, using $\mathrm{Sr}$ and ${ }^{87} \mathrm{Sr} /{ }^{86} \mathrm{Sr}$ variations in tributaries and along the 10 $\mathrm{km}$ segment of the downstream river water, shows an $\sim 80 \%$ increase of dissolved constituents originating from predominantly active MTM operations. Leaching experiments of the local watershed rocks confirm that the elevated salinity, high $\mathrm{Ca}$ and $\mathrm{SO}_{4}$ contents, and $\mathrm{Sr} / \mathrm{Ca}$ and ${ }^{87} \mathrm{Sr} /{ }^{86} \mathrm{Sr}$ fingerprints of the leachates directly reflect the compositions of MTM effluents. These results provide new geochemical tools to delineate and monitor the mobilization and potential impact of dissolved constituents derived from leaching of residual rocks in VFs associated with surface MTM operations.

\section{ASSOCIATED CONTENT}

\section{S Supporting Information}

Additional details on the watershed geology, core stratigraphy, and chemical and isotopic variations of the Mud River and tributaries from the valley fills, along with chemical data of the leaching experiments. This material is available free of charge via the Internet at http://pubs.acs.org.

\section{AUTHOR INFORMATION}

\section{Corresponding Author}

*Phone: (919) 681-8050. Fax: (919) 684-5833. E-mail: vengosh@duke.edu.

\section{Notes}

The authors declare no competing financial interest.

\section{ACKNOWLEDGMENTS}

We thank William Chameides, the Dean of the Nicholas School of Environment, for supporting this research. We also thank three anonymous reviewers and the editor for improving the manuscript. We gratefully acknowledge the long-term financial support from Fred and Alice Stanback to the Nicholas School of Environment.

\section{REFERENCES}

(1) The Effects of Mountaintop Mines and Valley Fills on Aquatic Ecosystems of the Central Appalachian Coalfields (External Review Draft); EPA/600/R-09/138A; U.S. Environmental Protection Agency: Washington, DC, 2010.

(2) Schnoor, J. L. Mountaintop Mining. Environ. Sci. Technol. 2010, 44, 8794-8794.

(3) Fulk, F. B.; Autrey, J.; Hutchens, J.; Gerritsen, J.; Burton, C. C.; Jessup, B. Ecological Assessment of Streams in the Coal Mining Region of West Virginia Using Data Collected by U.S. EPA and Environmental 
Consulting Firms; National Exposure Research Laboratory, U.S. Environmental Protection Agency: Washington, DC, 2003.

(4) Phillips, J. D. Impacts of surface mine valley fills on headwater floods in eastern Kentucky. Environ. Geol. 2004, 45, 367-380.

(5) Hartman, K. J.; Kaller, M. D.; Howell, J. W.; Sweka, J. A. How much do valley fills influence headwater streams? Hydrobiologia 2005, 532, 91-102.

(6) Wickham, J. D.; Riitters, K. H.; Wade, T. G.; Coan, M.; Homer, C. The effect of Appalachian mountaintop mining on interior forest. Landscape Ecol. 2007, 22, 179-187.

(7) Pond, G. J.; Passmore, M. E.; Borsuk, F. A.; Reynolds, L.; Rose, C. J. Downstream effects of mountaintop coal mining: Comparing biological conditions using family- and genus-level macroinvertebrate bioassessment tools. J. North Am. Benthol. Soc. 2008, 27, 717-737.

(8) Gilbert, N. Environment mountaintop mining plans close to defeat. Nature 2010, 467, 1021-1021.

(9) Palmer, M. A.; Bernhardt, E. S.; Schlesinger, W. H.; Eshleman, K. N.; Foufoula-Georgiou, E.; Hendryx, M. S.; Lemly, A. D.; Likens, G. E.; Loucks, O. L.; Power, M. E.; White, P. S.; Wilcock, P. R. Mountaintop mining consequences. Science 2010, 327, 148-149.

(10) Pond, G. J. Patterns of Ephemeroptera taxa loss in Appalachian headwater streams (Kentucky, USA). Hydrobiologia 2010, 641, 185201.

(11) Dittman, E. K.; Buchwalter, D. B. Manganese bioconcentration in aquatic insects: $\mathrm{Mn}$ oxide coatings, molting loss, and $\mathrm{Mn}$ (II) thiol scavenging. Environ. Sci. Technol. 2010, 44, 9182-9188.

(12) Pumure, I.; Renton, J. J.; Smart, R. B. The interstitial location of selenium and arsenic in rocks associated with coal mining using ultrasound extractions and principal component analysis (PCA). J Hazard. Mater. 2011, 198, 151-158.

(13) Bernhardt, E. S.; Palmer, M. A. The environmental costs of mountaintop mining valley fill operations for aquatic ecosystems of the central Appalachians. Ann. N.Y. Acad. Sci. 2011, 1223, 39-57.

(14) Bernhardt, E. S.; Lutz, B. D.; King, R. S.; Fay, J. P.; Carter, C. E.; Helton, A. M.; Campagna, D.; Amos, J. How many mountains can we mine? Assessing the regional degradation of central Appalachian rivers by surface coal mining. Environ. Sci. Technol. 2012, 46, 8115-8122.

(15) Lindberg, T. T.; Bernhardt, E. S.; Bier, R.; Helton, A. M.; Merola, R. B.; Vengosh, A.; Di Giulio, R. T. Cumulative impacts of mountaintop mining on an Appalachian watershed. Proc. Natl. Acad. Sci. U.S.A. 2011, 108, 20929-20934.

(16) Griffith, M. B.; Norton, S. B.; Alexander, L. C.; Pollard, A. I.; LeDuc, S. D. The effects of mountaintop mines and valley fills on the physicochemical quality of stream ecosystems in the central Appalachians: A review. Sci. Total Environ. 2012, 417-418.

(17) Agouridis, C. T.; Angel, P. N.; Taylor, T. J.; Barton, C. D.; Warner, R. C.; Yu, X.; Wood, C. Water quality characteristics of discharge from reforested loose-dumped mine spoil in eastern Kentucky. J Environ. Qual. 2012, 41, 454-468.

(18) A Field-Based Aquatic Life Benchmark for Conductivity in Central Appalachian Streams (External Review Draft); EPA/600/R-10/0234A; U.S. Environmental Protection Agency: Washington, DC, 2010.

(19) Fedorko, N., Blake, M. A Geologic Overview of Mountaintop Removal Mining in West Virginia, 1998. http://www.wvgs.wvnet.edu/ www/mtrm/wvgesmtr.pdf (accessed July 2013).

(20) Grady, W. C.; Eble, C. F.; Ashton, K. C. Characteristics and Utilization of Kanawha Formation Splint Coals in Central and Southern West Virginia; AAPG Eastern Section, AAPG: Charleston, WV, 1988.

(21) Vesper, D. J.; Roy, M.; Rhoads, C. J. Selenium distribution and mode of occurrence in the Kanawha Formation, southern West Virginia, USA. Int. J Coal Geol. 2008, 73, 237-249.

(22) Blowes, D. W.; Ptacek, C. J.; Jambor, J. L.; Weisener, C. G. The Geochemistry of Acid Mine Drainage; In Treatise on Geochemistry; Heinrich, D. H., Karl, K. T., Eds.; Pergamon: Oxford, 2003; pp 149204.

(23) Aranda, S.; Borrok, D. M.; Wanty, R. B.; Balistrieri, L. S. Zinc isotope investigation of surface and pore waters in a mountain watershed impacted by acid rock drainage. Sci. Total Environ. 2012, 420, 202-213.
(24) Atekwana, E. A.; Fonyuy, E. W. Dissolved inorganic carbon concentrations and stable carbon isotope ratios in streams polluted by variable amounts of acid mine drainage. J. Hydrol. 2009, 372, 136-148.

(25) Brubaker, T. M.; Stewart, B. W.; Capo, R. C.; Schroeder, K. T.; Chapman, E. C.; Spivak-Birndorf, L. J.; Vesper, D. J.; Cardone, C. R.; Rohar, P. C. Coal fly ash interaction with environmental fluids: Geochemical and strontium isotope results from combined column and batch leaching experiments. Appl. Geochem. 2013, 32, 184-194.

(26) Chapman, E. C.; Capo, R. C.; Stewart, B. W.; Hedin, R. S.; Weaver, T. J.; Edenborn, H. M. Strontium isotope quantification of siderite, brine and acid mine drainage contributions to abandoned gas well discharges in the Appalachian Plateau. Appl. Geochem. 2013, 31, $109-118$.

(27) Edraki, M.; Golding, S. D.; Baublys, K. A.; Lawrence, M. G. Hydrochemistry, mineralogy and sulfur isotope geochemistry of acid mine drainage at the Mt. Morgan mine environment, Queensland, Australia. Appl. Geochem. 2005, 20, 789-805.

(28) Fonyuy, E. W.; Atekwana, E. A. Effects of acid mine drainage on dissolved inorganic carbon and stable carbon isotopes in receiving streams. Appl. Geochem. 2008, 23, 743-764.

(29) Gammons, C. H.; Brown, A.; Poulson, S. R.; Henderson, T. H. Using stable isotopes $(\mathrm{S}, \mathrm{O})$ of sulfate to track local contamination of the Madison karst aquifer, Montana, from abandoned coal mine drainage. Appl. Geochem. 2013, 31, 228-238.

(30) Hubbard, C. G.; Black, S.; Coleman, M. L. Aqueous geochemistry and oxygen isotope compositions of acid mine drainage from the Rio Tinto, SW Spain, highlight inconsistencies in current models. Chem. Geol. 2009, 265, 321-334.

(31) Sharma, S.; Sack, A.; Adams, J. P.; Vesper, D. J.; Capo, R. C.; Hartsock, A.; Edenborn, H. M. Isotopic evidence of enhanced carbonate dissolution at a coal mine drainage site in Allegheny County, Pennsylvania, USA. Appl. Geochem. 2013, 29, 32-42.

(32) Collection of Water Samples (ver. 2.0), U.S. Geological Survey Techniques of Water-Resources Investigations, Book 9, Chapter A4; U.S. Geological Survey: Reston, VA, 2006, p 231. http://water.usgs. gov/owq/FieldManual/chapter4/pdf/Chap4_v2.pdf (accessed July 2013).

(33) Fox, J. F.; Campbell, J. E. Terrestrial carbon disturbance from mountaintop mining increases lifecycle emissions for clean coal. Environ. Sci. Technol. 2010, 44, 2144-2149.

(34) Cook, P. G.; Herczeg, A. L. Environmental Tracers in Subsurface Hydrology; Springer: New York, 2000; p 529.

(35) Saltzman, M. R; Thomas, E. Carbon Isotope Stratigraphy. In The Geologic Time Scale; Elsevier: Boston, 2012; Chapter 11, pp 207232.

(36) Fitzhugh, R. D.; Furman, T.; Korsak, A. K. Sources of stream sulphate in headwater catchments in Otter Creek Wilderness, West Virginia. Hydrol. Proc. 2001, 15, 541-556.

(37) Finley, J. B.; Drever, J. I.; Turk, J. T. Sulfur isotope dynamics in a high-elevation catchment, West Glacier Lake, Wyoming. Water, Air, Soil Pollut. 1995, 79, 227-241.

(38) Daniels, W. L.; Beck, M.; Eick, M.; Orndorff, Z. Predicting Contaminant Leaching Potentials for Central Appalachian Overburden and Coal Refuse Materials; Department of Crop and Soil Environmental Sciences, Virginia Tech: Blacksburg, VA, 2009. http://www. techtransfer.osmre.gov/nttmainsite/appliedscience/2007/Projects/ VTLeachingPotentialNPointon07FR.pdf (accessed July 2013).

(39) Plant, J. A.; Kinniburgh, D. G.; Smedley, P. L.; Fordyce, F. M.; Klinck, B. A. Arsenic and Selenium. In Treatise on Geochemistry; Heinrich, D. H., Karl, K. T., Eds.; Pergamon: Oxford, 2003; pp 17-66. 